\title{
Seleção de flexibilidades de manufatura: uma analogia à carteira de ações para minimização de riscos e problemas no ambiente fabril
}

\author{
Manufacturing flexibility selection: an analogy to the \\ stock portfolio management for risk and problem \\ minimization in the manufacturing environment
}

\author{
Ualison Rébula Oliveira' \\ Fernando Augusto Silva Marins ${ }^{1}$ \\ Paulo Roberto Tavares Dalcol²
}

\begin{abstract}
Resumo: Para empresas de manufatura, vários autores recomendam a utilização da flexibilidade de manufatura para a minimização dos impactos prejudiciais que os riscos incutem às organizações. Entretanto, a característica multidimensional da flexibilidade de manufatura e os trade-offs existentes entre os diversos tipos dificultam a tarefa de se selecionar e adequar o grau de flexibilidade a ser adotado, frente às variáveis existentes. Além disso, a escolha indevida de tipos de flexibilidade para a solução de problemas pode gerar investimentos desnecessários e inadequados, ocasionando perda de capital e ineficiência no uso dos recursos flexíveis escolhidos para antecipação aos riscos. Assim, disponibilizar à gestão de operações resultados que permitam a seleção de diferentes tipos de flexibilidade, segundo as necessidades e a disponibilidade de recursos de cada empresa, torna-se crucial. Com esse propósito, efetuou-se uma pesquisa empírica que contemplou oito empresas de cinco segmentos industriais, na qual, por meio de uma analogia à diversificação de riscos em carteira de ações, propõe-se a composição de cinco diferentes tipos de carteiras de flexibilidades, para cinco diferentes segmentos industriais.
\end{abstract}

Palavras-chave: Riscos. Seleção de tipos de flexibilidade. Flexibilidade de manufatura. Pesquisa empírica. Indústria. Carteira de ações.

\begin{abstract}
Many authors recommend the use of manufacturing flexibility to minimize the harmful effects that risks instill in manufacturing companies. However, the multidimensional feature of manufacturing flexibility and the several different types of trade-offs make it difficult to select and customize the flexibility level to be adopted due to the existing variables. Moreover, choosing wrong types of flexibility for the solution of problems may lead to unnecessary and inadequate investments resulting in capital loss and inefficiency in the use of flexible resources for risk anticipation. Therefore, it becomes crucial to provide operations management with results that allow the selection of different types of flexibility according to the company's needs and resources availability. Hence, an empirical research contemplating eight companies from five industrial segments was carried out by means of an analogy with risks diversification in stock portfolios. Five different types of flexibility portfolios are proposed for five different industrial segments.
\end{abstract}

Keywords: Risks. Flexibility type selection. Manufacturing flexibility. Empirical research. Industry. Stock portfolio.

\section{Introdução}

No passado, a demanda era mais estável, havia menos variedade de produtos e ciclos de vida eram mais longos (BEACH et al., 2000). Entretanto, ao longo das duas últimas décadas, as empresas industriais se depararam com um mercado caracterizado por mudanças sem precedentes (SCALA; PURDY;
SAFAYENI, 2006). Nesse ambiente, para se manterem competitivas, muitas organizações tiveram que lutar com menores lotes de produção, produtos personalizados, aumento dos níveis de concorrência e rápidas mudanças no mercado (CORREA, 1994).

Segundo Bengtsson, Olhager (2002), para reagir ao aumento das mudanças, da redução do ciclo de

\footnotetext{
Departamento de Produção, Faculdade de Engenharia do Campus de Guaratinguetá, Universidade Estadual Paulista "Julio de Mesquita Filho", Av. Ariberto Pereira da Cunha, 333, CEP12516-410, Guaratinguetá - SP, Brasil, E-mail: ualison.oliveira@ gmail.com

2 Departamento de Engenharia Industrial, Pontifícia Universidade Católica do Rio de Janeiro "PUC-Rio", Rua Marques de São Vicente, 225, Gávea, CEP 22453-900, Rio de Janeiro - RJ, Brasil, E-mail: prtd@ puc-rio.br
} 
vida dos produtos e da comercialização globalizada, a flexibilidade está se tornando uma importante fonte de vantagem competitiva para a manufatura. Nessa mesma linha de pensamento, Serrão (2001) defende que a flexibilidade de manufatura se tornou um elemento de diferenciação da competitividade entre as empresas, afirmando que dentre as fontes mais difundidas (custo, tempo, qualidade e flexibilidade), a flexibilidade de manufatura tem emergido como um elemento-chave para as organizações. Slack (2005), também classifica a flexibilidade como uma fonte de vantagem competitiva, advertindo que a manufatura necessita ser flexível porque ela tem de administrar a operação sob condições de variedade, riscos e incertezas, permitindo que o processo produtivo continue o seu trabalho.

Slack (1983) cita que, com a crescente demanda dos consumidores por rápidas respostas e grande variedade de produtos, aliado a um cenário em que a competição é cada vez mais acirrada, a flexibilidade é a solução para muitos problemas do gênero, visto que ela contribui para o desempenho da manufatura, melhorando variáveis como pontualidade, custos e velocidade. A pontualidade, por exemplo, é melhorada quando a manufatura é flexível o suficiente para lidar com interrupções inesperadas no fornecimento, problemas de entrega e capacidade de processo.

Para organizações caracterizadas pela customização, sob prazos curtos, com preferências do consumidor em constante mudança e elevada incerteza, a flexibilidade em manufatura não é apenas desejável, mas está rapidamente se tornando um requisito para a sobrevivência organizacional (NORDAHL; NILSSON, 1996; BOYLE, 2006; BAYKASOGLU; OZBAKIR, 2008; WAHAB; WU; LEE, 2008).
Apesar da existência de importantes avanços nas duas últimas décadas sobre o tema manufatura flexível, há muito trabalho que deve ser feito para elevar o entendimento desse complexo fenômeno (KARA; KAYIS, 2004). Corrêa (1994), por exemplo, observou que, não obstante a existência de algum tipo de relação entre incerteza e flexibilidade, mais pesquisa seria necessária para prover, tanto o suporte empírico para estas relações, como uma maior compreensão dos mecanismos que as regem.

Exatamente nesse sentido, o presente artigo buscou, por meio de pesquisa empírica, o aprofundamento em estudos sobre flexibilidade de manufatura que possibilitem seu entendimento e, consequentemente, que permitam as organizações industriais lidarem com os mais variados riscos e incertezas da atualidade.

A pesquisa focou a influência das dimensões da flexibilidade sobre os riscos e problemas que ocorrem na manufatura, baseando-se em levantamento da percepção dos funcionários de nível tático e limitando-se ao ambiente produtivo de oito empresas de cinco segmentos industriais diferentes. $\mathrm{O}$ estudo utilizou uma amostra de cinco respondentes de cada uma das empresas pesquisadas, totalizando um total de quarenta entrevistados. O Quadro 1 mostra algumas características dos respondentes e de suas respectivas empresas.

A dificuldade nesse estudo está no fato de que existem inúmeros tipos de flexibilidade de manufatura, surgindo aí a necessidade de se estabelecer prioridades na escolha adequada destas flexibilidades, para os diferentes tipos de riscos que ocorrem no ambiente produtivo.

Quadro 1. Qualificação das empresas pesquisadas e seus respondentes.

\begin{tabular}{|c|c|c|c|c|}
\hline $\begin{array}{c}\text { Empresa } \\
\text { pesquisada }\end{array}$ & $\begin{array}{c}\text { O que as } \\
\text { empresas } \\
\text { produzem }\end{array}$ & $\begin{array}{l}\text { Estado em que } \\
\text { a empresa está } \\
\text { localizada }\end{array}$ & $\begin{array}{l}\text { Características dos } \\
\text { funcionários que } \\
\text { preencheram o } \\
\text { questionário na Internet }\end{array}$ & $\begin{array}{l}\text { Período em que os } \\
\text { instrumentos de coletas de } \\
\text { dados foram preenchidos }\end{array}$ \\
\hline $\begin{array}{l}\text { Montadora de } \\
\text { veículos um }\end{array}$ & $\begin{array}{c}\text { Automóveis de } \\
\text { passeio e utilitários }\end{array}$ & Rio de Janeiro & $\begin{array}{l}\text { Nível tático e que trabalha } \\
\text { diretamente na manufatura }\end{array}$ & Novembro de 2008 \\
\hline $\begin{array}{l}\text { Montadora de } \\
\text { veículos dois }\end{array}$ & $\begin{array}{l}\text { Caminhões e } \\
\text { ônibus }\end{array}$ & Rio de Janeiro & $\begin{array}{l}\text { Nível tático e que trabalha } \\
\text { diretamente na manufatura }\end{array}$ & Novembro de 2008 \\
\hline $\begin{array}{l}\text { Montadora de } \\
\text { veículos três }\end{array}$ & $\begin{array}{c}\text { Automóveis de } \\
\text { passeio e utilitários }\end{array}$ & Bahia & $\begin{array}{l}\text { Nível tático e que trabalha } \\
\text { diretamente na manufatura }\end{array}$ & $\begin{array}{c}\text { Novembro e } \\
\text { Dezembro de } 2008\end{array}$ \\
\hline $\begin{array}{l}\text { Montadora de } \\
\text { veículos quatro }\end{array}$ & $\begin{array}{c}\text { Automóveis de } \\
\text { passeio e utilitários }\end{array}$ & São Paulo & $\begin{array}{l}\text { Nível tático e que trabalha } \\
\text { diretamente na manufatura }\end{array}$ & $\begin{array}{c}\text { Novembro e } \\
\text { Dezembro de } 2008\end{array}$ \\
\hline $\begin{array}{l}\text { Indústria } \\
\text { química }\end{array}$ & $\begin{array}{l}\text { Agrotóxicos, } \\
\text { adubos e pesticidas }\end{array}$ & Rio de Janeiro & $\begin{array}{l}\text { Nível tático e que trabalha } \\
\text { diretamente na manufatura }\end{array}$ & Novembro de 2008 \\
\hline $\begin{array}{l}\text { Indústria de } \\
\text { vidros }\end{array}$ & Vidros planos & Rio de Janeiro & $\begin{array}{l}\text { Nível tático e que trabalha } \\
\text { diretamente na manufatura }\end{array}$ & $\begin{array}{l}\text { Novembro e Dezembro de } \\
2008 \text { e Janeiro de } 2009\end{array}$ \\
\hline $\begin{array}{l}\text { Indústria de } \\
\text { equipamentos }\end{array}$ & $\begin{array}{l}\text { Equipamentos } \\
\text { eletrônicos }\end{array}$ & Rio de Janeiro & $\begin{array}{l}\text { Nível tático e que trabalha } \\
\text { diretamente na manufatura }\end{array}$ & Novembro de 2008 \\
\hline $\begin{array}{l}\text { Indústria de } \\
\text { pneus }\end{array}$ & Pneus & Rio de Janeiro & $\begin{array}{l}\text { Nível tático e que trabalha } \\
\text { diretamente na manufatura }\end{array}$ & $\begin{array}{l}\text { Novembro e Dezembro de } \\
2008 \text { e Janeiro de } 2009\end{array}$ \\
\hline
\end{tabular}


Trata-se de um importante problema de tomada de decisão, uma vez que a escolha indevida de tipos de flexibilidade para a solução de problemas impactará em investimentos desnecessários e inadequados, gerando perda de capital, a indisponibilidade e ineficiência dos recursos flexíveis escolhidos para a solução de problemas.

Como solução para esse problema de tomada de decisão, neste trabalho, vislumbram-se analogias às pesquisas de diversificação de riscos no mercado de ações, por meio de composição de carteiras de ações.

No mercado de ações, a partir de estudos de Markowitz (1952) e Sharpe (1964), foi estabelecida uma relação entre risco e retorno, sendo possível a redução do risco a partir da aglutinação de diferentes tipos de ações (carteira de ações).

A contribuição da pesquisa aqui relatada está em identificar uma analogia com a seleção de carteiras de ações, trazendo esse contexto para dentro da gestão de operações, em que se pretende fazer a seleção de diferentes tipos de flexibilidade de manufatura para a minimização (ou até mesmo eliminação) dos efeitos indesejados dos riscos que afetarem a manufatura.

O trabalho está estruturado como se segue. A seção 2, segmentada em flexibilidade de manufatura e carteira de ações, aborda o referencial teórico que traz sustentabilidade ao artigo, listando conceitos sobre flexibilidade de manufatura, tipos de flexibilidade de manufatura, carteira de ações, seleção de carteira de ações, riscos de ações e diversificação de riscos de ações. A seção 3 aborda a pesquisa empírica em oito empresas de cinco segmentos industriais distintos, organizando, analisando e interpretando os resultados. E, por fim, a seção 4 apresenta a conclusão do estudo.

\section{Carteira de ações e flexibilidade de manufatura}

Aqui se faz uma revisão sobre o referencial teórico de carteira de ações e flexibilidade de manufatura.

\subsection{Carteiras de ações}

Na maior parte dos investimentos, um indivíduo ou empresa faz aplicações de recursos financeiros na expectativa de um resultado futuro, esperando sempre um maior nível de retorno e um menor nível de risco (ROSS; WESTERFIELD; JAFFE, 2002). O risco decorre da probabilidade dos retornos efetivos serem menores do que o retorno esperado - quanto maior a chance de um retorno baixo ou negativo, mais arriscado é o investimento (BRIGHAM; GAPENSKI; EHRTARDT, 2001).

Para a minimização dos riscos, Treynor, Black (1973) recomendam a diversificação dos ativos por meio de uma seleção de carteira de ações, de forma a compor o que Markowitz (1952) chamou de 'carteira de ações'. Markowitz (1952) descobriu que a combinação de ativos minimamente correlacionados em uma carteira de ações diminuía o risco total do investidor, sem afetar seu retorno esperado.

Seleção de carteiras de ações é o estudo de como se pode investir em ações de forma que ela possua o maior retorno esperado e o menor risco possível. É um processo para compensar o risco e o retorno esperado, de forma a encontrar a melhor combinação de ativos (LAKONISHOK; SHLEIFER; VISHNY, 1994).

Segundo Ross, Westerfield, Jaffe (2002) e Brigham, Gapenski e Ehrtardt (2001), uma carteira é uma combinação de ativos, em que o retorno esperado é simplesmente uma média ponderada dos retornos esperados dos títulos que a compõem.

Entretanto, diferentemente dos retornos, o risco de uma carteira $\sigma_{\mathrm{p}}$, geralmente não é a média ponderada dos desvios padrão dos ativos individuais; o risco da carteira, em princípio, pode ser bastante diferente dos riscos dos ativos que a compõem. Isso pode ser observado no Quadro 2, que ilustra médias típicas de desvios padrão de carteiras que contêm diferentes quantidades de títulos negociados na New York Stock Exchange (NYSE), selecionadas aleatoriamente.

Na coluna 2 do Quadro 2, observa-se que o desvio padrão de uma carteira de um único titulo é cerca

Quadro 2. Quantas ações fazem a diversificação de um portfólio. Fonte: Enton; Gruber, 1987 (apud ROSS; WESTERFIELD; JAFFE, 2002).

\begin{tabular}{|ccc|}
\hline $\begin{array}{c}\text { Número de } \\
\text { ações da carteira }\end{array}$ & $\begin{array}{c}\text { Desvio padrão médio dos } \\
\text { retornos anuais da carteira }(\%)\end{array}$ & $\begin{array}{c}\text { Razão entre o desvio padrão da carteira e o } \\
\text { desvio padrão de uma única ação }\end{array}$ \\
\hline 1 & 49,24 & 1,00 \\
2 & 37,76 & 0,76 \\
4 & 29,69 & 0,60 \\
6 & 26,64 & 0,54 \\
8 & 24,98 & 0,51 \\
10 & 23,93 & 0,49 \\
50 & 20,20 & 0,41 \\
100 & 19,69 & 0,40 \\
1000 & 19,21 & 0,39 \\
\hline
\end{tabular}


de $49 \%$. Isso significa que, se for selecionada uma única ação da NYSE e nela for investido todo o recurso disponível, o desvio padrão dos retornos tipicamente terá um nível substancial de $49 \%$ ao ano. Se fossem selecionadas, aleatoriamente, duas ações e investido metade dos recursos disponíveis em cada uma, o desvio padrão seria cerca de $37 \%$, em média, e assim por diante.

No Quadro 2, observa-se, ainda, que o desvio padrão da carteira diminui à medida que o número de títulos aumenta. Quando se tem por volta de 100 ações, o desvio padrão da carteira diminui cerca de $60 \%$, ou seja, de $49 \%$ para $20 \%$. Com 500 ações, o desvio é 19,27\%. A Figura 1 resume essa análise.

Outra constatação importante é a de que o risco de uma carteira depende não somente do risco de cada elemento que a compõe e/ou de sua participação no investimento total, mas também da forma com que seus componentes se relacionam entre si (ASSAF NETO, 2003). Conforme Brigham, Gapenski e Ehrtardt (2001), a tendência de duas variáveis moverem-se juntas é chamada correlação e o coeficiente de correlação mede essa tendência. Correlação é uma medida estatística da relação entre duas séries quaisquer de números. Os números podem representar dados de qualquer tipo, de retorno de investimento a pontuações de teste. Se duas séries se movem na mesma direção, são positivamente correlacionadas; se duas séries se movem em direções opostas, são negativamente correlacionadas (TRIOLA, 2005).

O grau de correlação é medido pelo coeficiente de correlação, que varia de +1 para correlação positivamente perfeita, a -1, para séries com correlação negativamente perfeita. Esses dois extremos são retratados na Figura 2. As séries sem correlação positivamente perfeita se movem exatamente juntas; as séries com correlação negativamente perfeita se movem em direções opostas.

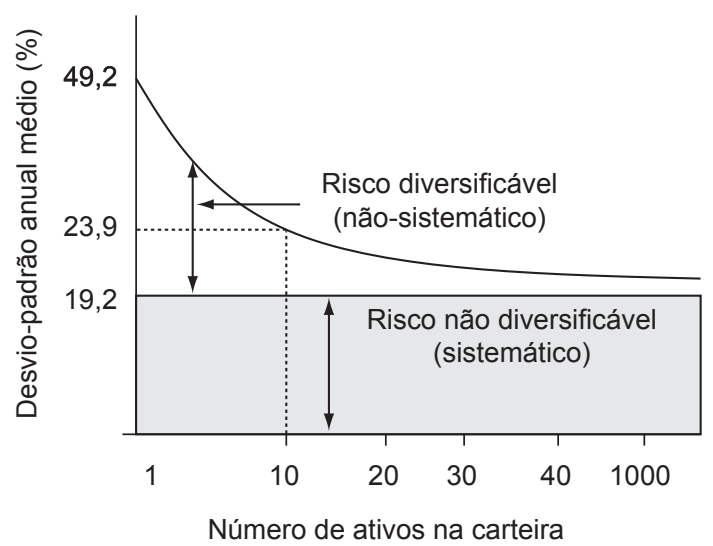

Figura 1. Correlação positiva. Fonte: Gitman e Madura (2003).
O conceito de correlação é essencial para desenvolver a carteira eficiente. Para reduzir o risco geral, é melhor combinar - ou acrescentar à carteira - ativos que tenham uma correlação negativa (ou positiva baixa) (ROSS; WESTERFIELD; JAFFE, 2002).

Segundo Gonçalves Jr., Pamplona e Montevechi (2002), combinar ativos negativamente correlacionados pode reduzir a variabilidade geral de retornos. Mesmo que os ativos não sejam negativamente correlacionados, quanto menor for a correlação positiva entre eles, menor será o risco resultante. Além disso, existem ainda os ativos não correlacionados - não há interação entre seus retornos. Combinar ativos não correlacionados pode reduzir o risco, embora não tão efetivamente quanto combinar ativos negativamente correlacionados.

Exemplificando como as diferentes correlações entre os ativos resultam em riscos distintos, Gitman e Madura (2003) fornecem uma ilustração dessa sistemática por meio do Quadro 3, que apresenta duas carteiras combinadas de formas diferentes. Uma carteira possui ativos correlacionados de forma perfeitamente positiva; outra carteira possui ativos correlacionados de forma perfeitamente negativa.

\subsection{Flexibilidade de manufatura}

A adequada interpretação e compreensão sobre o que significa flexibilidade de manufatura tem-se
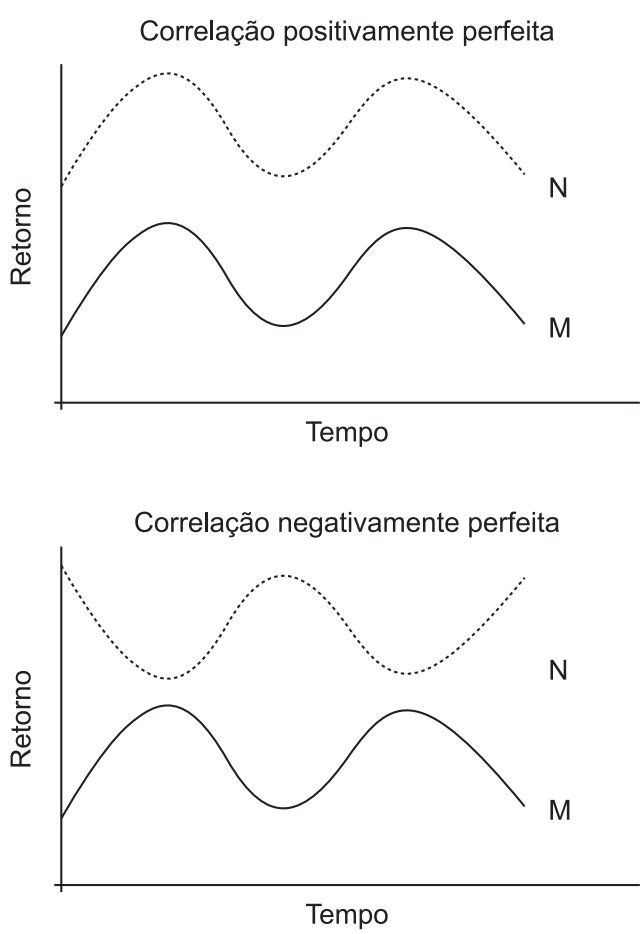

Figura 2. Correlação positiva. Fonte: Gitman e Madura (2003). 
revelado complexa, tanto para os profissionais que procuram orientação quanto para os acadêmicos que pesquisam sobre o tema (GUPTA; SOMERS, 1992; OKE, 2005; CHANG et al., 2007).

Diante disso, aqui se desenvolveu uma definição própria e pertinente aos propósitos do trabalho, oriunda da definição inicial de vários pesquisadores sobre o tema, que seria a seguinte: A flexibilidade de manufatura é a habilidade (ZUKIN; DALCOL, 2000), capacidade (GUSTAVSSON, 1984), rapidez (COX, 1989), competência (SUAREZ; CUSUMANO; FINE, 1995) e aptidão (DE TONI; TONCHIA, 1998) que uma organização possui para mudar ou reagir (SLACK, 1983), diante das modificações ocorridas no ambiente de manufatura (GUPTA; GOYAL, 1989), considerando tempo, custo e esforço envolvidos (UPTON, 1997).

Quanto à sua utilidade, Correa (1994) julga que a flexibilidade surge por conta da necessidade de lidar com incertezas intrínsecas e variabilidade de saídas de processos. As incertezas e variabilidades levam às mudanças, sendo estas tanto planejadas (acontecem como decisão consciente da organização, tomada para alterar a própria organização ou sua relação com o ambiente) como não planejadas (acontecem independentemente da determinação da organização, mas às quais a organização precisa se adaptar).

Correa (1994) também sugeriu que incerteza ambiental e variabilidade nos resultados são as duas principais razões (ou estímulos) para a busca da flexibilidade de manufatura. Já as fontes de estímulos poderiam ser processo, fornecedores, clientes, sociedade, corporação, outras funções e concorrentes. Segundo o autor, as mudanças não planejadas têm cinco dimensões principais: tamanho, novidade, frequência, certeza e taxa. Como consequência, os gestores buscam manter controle sobre a situação, sendo a flexibilidade a forma buscada, como sugere o modelo da Figura 3.
Kara e Kayis (2004) discorrem sobre as necessidades que levam à flexibilidade, como pode ser visto na Figura 4.

De acordo com Upton $(1994,1995)$ e Boyle (2006), a flexibilidade em manufatura pode existir em diferentes níveis da organização (estratégico, tático e operacional) e é composta por vários tipos diferentes,

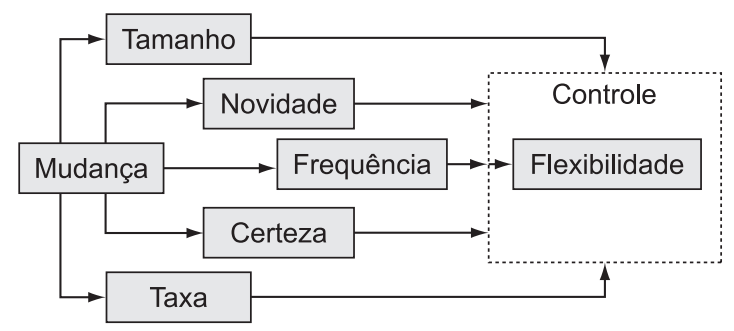

Figura 3. Ligações entre dimensões de mudança e flexibilidade. Fonte: Correa (1994).

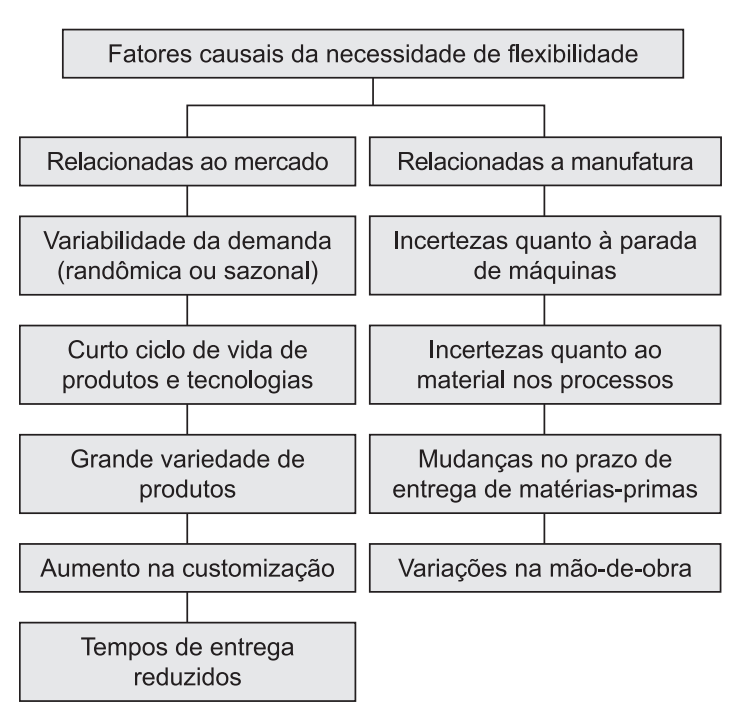

Figura 4. Fatores causais da necessidade de flexibilidade. Fonte: Kara e Kayis (2004).

Quadro 3. Exemplo de diversificação de ativos de diferentes graus de correlação. Fonte: Gitman e Madura (2003).

\begin{tabular}{|c|c|c|c|c|c|}
\hline \multicolumn{6}{|c|}{ Retornos, valores esperados e desvios padrão previstos para ativos $\mathrm{X}, \mathrm{Y}$ e $\mathrm{Z}$ e para as carteiras $\mathrm{XY}$ e $\mathrm{XZ}$} \\
\hline & \multicolumn{3}{|c|}{ Ativos } & \multicolumn{2}{|c|}{ Carteiras } \\
\hline Ano & $\mathbf{X}$ & $\mathbf{Y}$ & $\mathbf{Z}$ & $(50 \% X+50 \% Y)$ & $(50 \% X+50 \% Z)$ \\
\hline 2002 & $8 \%$ & $16 \%$ & $8 \%$ & $12 \%$ & $8 \%$ \\
\hline 2003 & 10 & 14 & 10 & 12 & 10 \\
\hline 2004 & 12 & 12 & 12 & 12 & 12 \\
\hline 2005 & 14 & 10 & 14 & 12 & 14 \\
\hline 2006 & 16 & 8 & 16 & 12 & 16 \\
\hline \multicolumn{6}{|c|}{ Dados estatísticos: } \\
\hline Valor esperado & $12 \%$ & $12 \%$ & $12 \%$ & $12 \%$ & $12 \%$ \\
\hline Desvio padrão & $3,16 \%$ & $3,16 \%$ & $3,16 \%$ & $0 \%$ & $3,16 \%$ \\
\hline
\end{tabular}


por exemplo, máquinas, roteirização, produto. Cada tipo pode ter diferentes aspectos, conhecidos como flexibilidade potencial, real e necessária, sendo medidos em termos do número de estados que podem ser alcançados (gama), da mobilidade (impactos gerados por mudanças, tais como custos e tempo para setup) e da uniformidade (em quanto as medidas de desempenho, tais como qualidade, se alteram com as mudanças executadas).

Especificamente sobre os tipos de flexibilidade de manufatura, há na literatura diferentes percepções. A concepção mais simples é a de Reid e Sanders (2005), que segmentaram a flexibilidade de manufatura em dois grandes tipos: a customização e a flexibilidade de volume. Já para Slack (1983), existem quatro tipos:

- Flexibilidade de novos produtos - habilidade de introduzir e produzir novos produtos ou de modificar os existentes;

- Flexibilidade de mix - habilidade de mudar a variedade dos produtos que estão sendo feitos pelas operações dentro de um dado período de tempo;

- Flexibilidade de volume - habilidade de mudar o nível agregado de saídas de operação; e

- Flexibilidade de entrega - habilidade de mudar datas de entrega planejadas.

Para Gupta e Goyal (1989), existem oito tipos de flexibilidade:

- Flexibilidade de máquina - a habilidade de repor ferramentas quebradas ou descartadas, mudar ferramentas em um magazine de ferramentas e reunir ou montar as estruturas necessárias, sem interferência ou longos períodos de setup;

- Flexibilidade de processo - habilidade de variar os passos necessários para completar uma tarefa;

- Flexibilidade de produto - habilidade para mudar a produção para um novo produto, dentro de um espectro de peças definido;

- Flexibilidade de rotina - habilidade de variar as sequências de uso da máquina para continuar a produção de um determinado conjunto de peças;

- Flexibilidade de volume - habilidade de operar um FMS (Flexibility Manufacturing System) lucrativamente em diferentes volumes de produção;

- Flexibilidade de expansão - a capacidade de construir um sistema e expandi-lo conforme necessário, fácil e de forma modular;

- Flexibilidade de sequência de processo - habilidade de trocar a ordem de diversas operações para cada tipo de peça; e

- Flexibilidade de produção - habilidade de rapidamente e economicamente mudar a variedade de peças para qualquer produto que um sistema de manufatura flexível possa produzir.

Para Koste e Malhotra (1999), existem dez dimensões de flexibilidade de manufatura, que foram observadas por esses autores em inúmeras pesquisas sobre o tema (Quadro 4). Já Vokurka e O'Leary-Kelly (2000) defendem doze dimensões, acrescentando as flexibilidades de produção e de entrega àquelas já propostas por Koste e Malhotra (1999).

Sethi, A. K.; Sethi, S. P. (1990) organizaram os tipos de flexibilidade em uma estrutura hierárquica, que reflete os diferentes níveis de operações dos sistemas de produção, além de mostrar suas ligações, como pode ser visto na Figura 5.

Suarez, Cusumano, Fine (1995; 1996) expuseram o conceito de que os diversos tipos de flexibilidade expressam seus efeitos nas chamadas flexibilidades básicas, ou de primeira ordem, - mix, volume, novos produtos e prazo de entrega -, os quais são percebidos diretamente pelo consumidor, afetando diretamente o posicionamento estratégico no mercado.

Koste e Malhotra (1999), do mesmo modo, estabeleceram uma escala hierárquica para flexibilidades que mostra os relacionamentos potenciais que existem entre elas, como de recurso individual, chão de fábrica, planta, funcional e de unidade estratégica de negócios, conforme se observa na Figura 6.

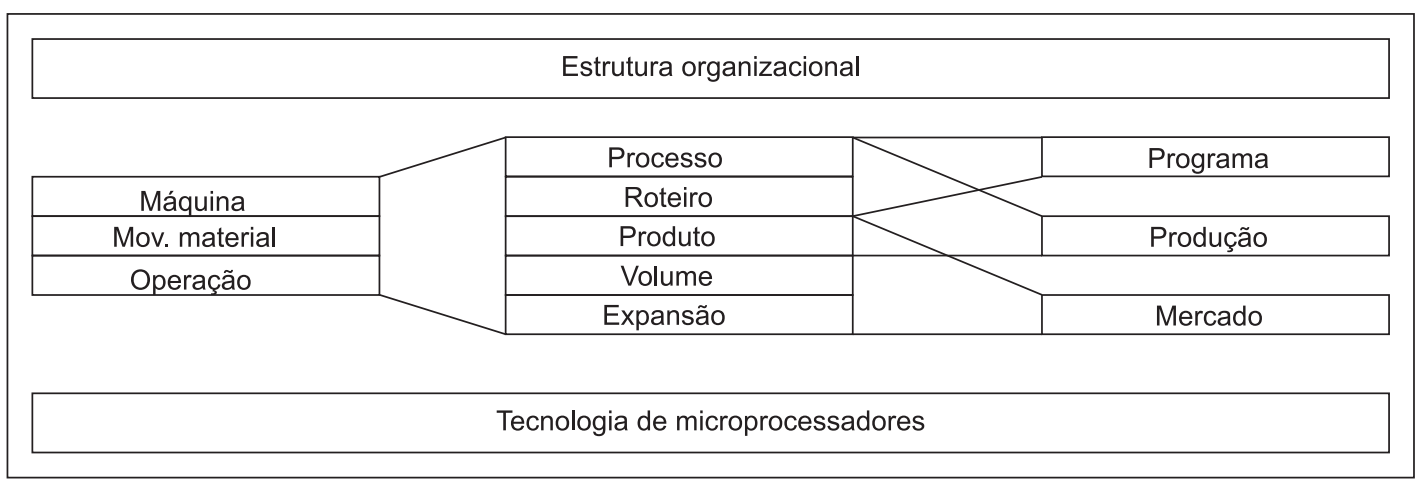

Figura 5. Ligações entre os vários tipos de flexibilidade. Fonte: Sethi, A. K.; Sethi, S. P. (1990) 
Quadro 4. Dimensões de flexibilidade de manufatura. Fonte: Koste e Malhotra (1999).

\begin{tabular}{|ll|}
\hline \multicolumn{1}{|c|}{ Dimensão } & \multicolumn{1}{c|}{ Definição } \\
\hline Máquina & $\begin{array}{l}\text { O número e a variedade de operações que uma máquina pode executar, sem incorrer em elevadas } \\
\text { penalidades de transição ou grandes mudanças nos resultados de desempenho. }\end{array}$ \\
Mão de obra & $\begin{array}{l}\text { O número e a variedade de tarefas/operações que um trabalhador pode executar sem incorrer em } \\
\text { elevadas penalidades de transição ou grandes mudanças nos resultados de desempenho. }\end{array}$ \\
$\begin{array}{l}\text { Movimentação de } \\
\text { material }\end{array}$ & $\begin{array}{l}\text { O número de caminhos existentes entre centros de processamento e a heterogeneidade (variedade) } \\
\text { de material que pode ser transportado ao longo desses caminhos sem incorrer em elevadas pena- } \\
\text { lidades de transição ou grandes mudanças nos resultados de desempenho. }\end{array}$ \\
Roteamento & $\begin{array}{l}\text { O número de produtos que têm rotas substitutas e a extensão das variações entre as rotas usadas } \\
\text { sem incorrer em penalidades de transição ou grandes mudanças nos resultados de desempenho. }\end{array}$ \\
Operação & $\begin{array}{l}\text { O número de produtos quem têm planos de sequenciamento substitutos e a variedade dos planos } \\
\text { usados sem incorrer em penalidades ou grandes mudanças nos resultados de desempenho. }\end{array}$ \\
Expansão & $\begin{array}{l}\text { O número e a variedade de expansões que podem ser acomodadas sem incorrer em elevadas pena- } \\
\text { lidades de transição ou grandes mudanças nos resultados de desempenho. }\end{array}$ \\
Volume & $\begin{array}{l}\text { A extensão das mudanças e o grau de flutuação no nível agregado de saídas que o sistema pode } \\
\text { acomodar sem incorrer em penalidades de transição ou grandes mudanças no desempenho. }\end{array}$ \\
Mix & $\begin{array}{l}\text { O número e a variedade (heterogeneidade) de produtos que podem ser produzidos sem incorrer } \\
\text { em elevadas penalidades de transição ou grandes mudanças nos resultados de desempenho. }\end{array}$ \\
Novos produtos & $\begin{array}{l}\text { O número e a variedade de novos produtos que são introduzidos na produção sem incorrer em } \\
\text { elevadas penalidades de transição ou grandes mudanças nos resultados de desempenho. }\end{array}$ \\
Modificação & $\begin{array}{l}\text { Onúmero e a variedade de modificações de produtos que são realizados sem incorrer em elevadas } \\
\text { penalidades de transição ou grandes mudanças nos resultados de desempenho. }\end{array}$ \\
\hline
\end{tabular}

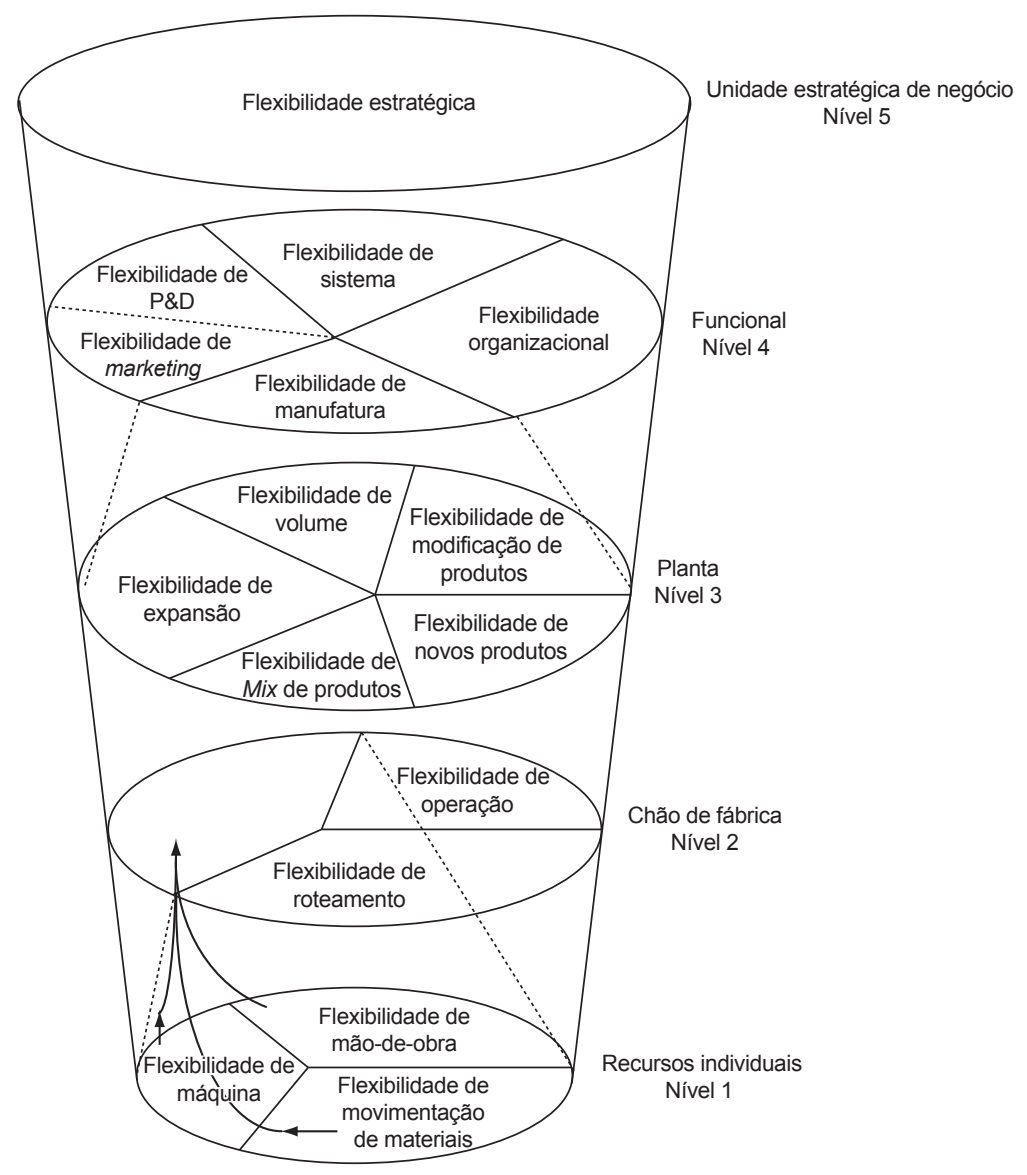

Figura 6. Hierarquia das dimensões da flexibilidade. Fonte: Koste e Malhotra (1999). 
De forma similar à correlação que existe no estudo de carteira de ações, na flexibilidade de manufatura existem os trade-offs entre os seus diferentes tipos. Gupta e Goyal (1989) afirmam que a sua compreensão pode aumentar a organização interna de um sistema flexível estruturado. Nessa linha de pesquisa, Suarez, Cusumano, Fine (1996) analisaram 31 plantas de produção de placas de circuitos impressos na Europa, Japão e Estados Unidos e constataram a existência de relacionamentos positivos e negativos entre variáveis envolvidas no processo.

A Figura 7 detalha os relacionamentos, identificados pelos autores entre dois tipos básicos de flexibilidades externas: flexibilidade de novos produtos e flexibilidade mix, com fatores e políticas que afetam ou não a flexibilidade. Nessa figura, o sinal "+" denota um relacionamento positivo, "0" denota o não relacionamento e "_" representa um relacionamento negativo.

Parker; Wirth (1999) igualmente estudaram as relações entre as dimensões de flexibilidade e seus elementos e identificaram a existência de relações complexas e trade-offs entre os tipos, conforme ilustra a Figura 8.

Na Figura 8 constata-se uma relação positiva entre a flexibilidade de processo (linha 2) e a flexibilidade de rotina (coluna 4); uma relação mista entre flexibilidade de rotina (linha 4) e a flexibilidade de volume (coluna 5); e uma relação negativa entre a flexibilidade de produto (linha 3 ) e a flexibilidade de volume (coluna 5). Demais constatações das relações entre as flexibilidades de manufatura podem ser analisadas da mesma forma que as anteriores. Para as células em branco não se pesquisou relacionamentos intra e entre as dimensões de flexibilidade.

Outra pesquisa relevante sobre os trade-offs das diferentes dimensões de flexibilidade de manufatura foi desenvolvida por Koste e Malhotra (2000). Os autores em questão pesquisaram dezoito trabalhos sobre o tema e constataram uma relação entre a flexibilidade de máquina e flexibilidade de mix, citada em dez pesquisas como sendo um requerimento da flexibilidade de produto e uma relação entre flexibilidade de máquina e flexibilidade de roteamento. Constataram, também, que cinco dimensões (expansão, volume, mix, novos produtos e modificação de produtos) não estão relacionadas com outras dimensões, indicando que estas dimensões não suportam o desenvolvimento das outras dimensões, mas são desenvolvidas por elas.

\section{Pesquisa empírica sobre flexibilidade de manufatura}

Após o levantamento bibliográfico sobre flexibilidade de manufatura, observou-se que, além da existência de diferentes tipos de flexibilidade, esses tipos possuem diferentes relações entre si; relações essas que podem afetar e influenciar positivamente ou negativamente umas às outras. Diante dessa constatação, efetuou-se uma pesquisa empírica em oito empresas, com a intenção de se descobrir, na prática, quais são os tipos de flexibilidade que mais ajudam a evitar problemas na manufatura e quais seriam as composições ideais de flexibilidade (diferentes tipos de flexibilidade selecionados e

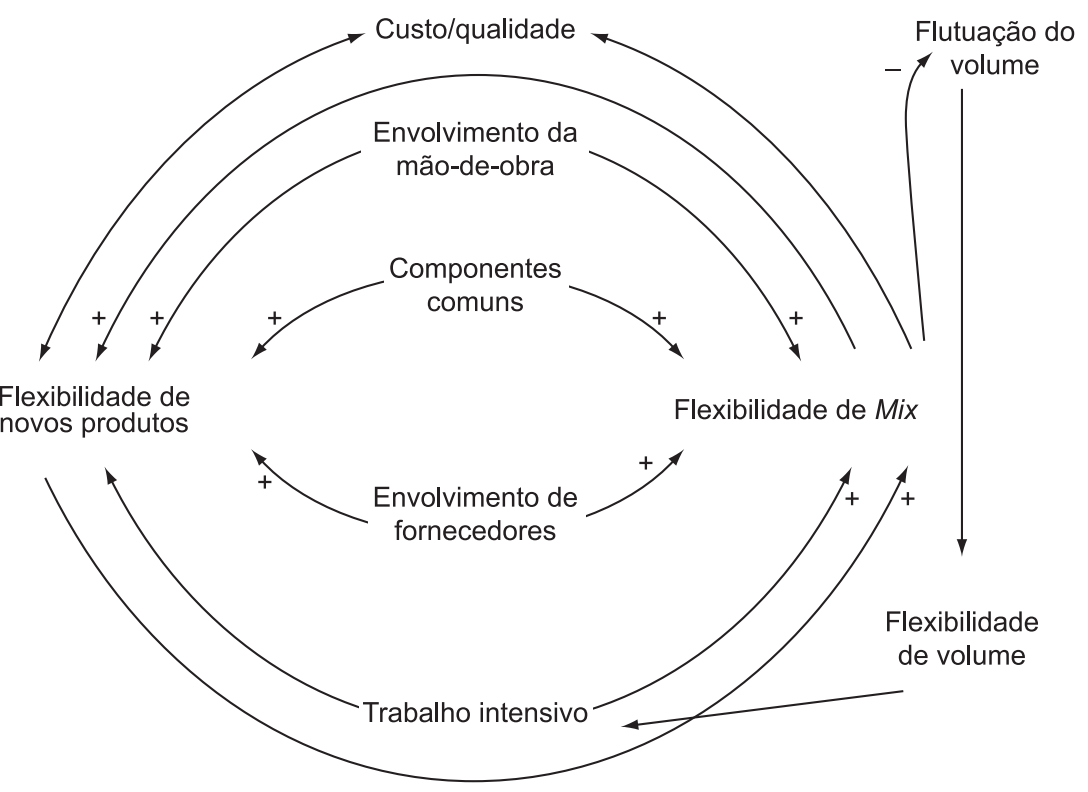

Figura 7. Diagrama de relacionamentos de flexibilidade. Fonte: Suarez, Cusumano Fine (1996). 


\begin{tabular}{|c|c|c|c|c|c|c|c|c|}
\hline & Máquina & Processo & Produto & Rotina & Volume & Expansão & Operação & Produção \\
\hline \multirow{6}{*}{$\begin{array}{l}\text { Máquina } \\
\text { Processo } \\
\text { Produto } \\
\text { Rotina } \\
\text { Volume } \\
\text { Exnansão }\end{array}$} & & ++ & ++ & ++ & -- & & ++ & ++ \\
\hline & & & ++ & ++ & -- & & & \\
\hline & & & & & -- & & & \\
\hline & & & & & +- & & ++ & \\
\hline & & & & & & & & \\
\hline & \multicolumn{8}{|c|}{ Expansão } \\
\hline \multicolumn{9}{|l|}{ Operação } \\
\hline Produção & & & & & & & & \\
\hline
\end{tabular}

++ relação positiva; - - relação negativa; + - relação mista.

Figura 8. Relação entre tipos de flexibilidade. Fonte: Parker e Wirth (1999).

aglutinados), dando uma ideia de 'carteira ideal de flexibilidade', de forma análoga ao que ocorre com as carteiras de ações.

Essa pesquisa empírica se fundamenta, sobretudo, nas ponderações de Swamidass e Newell (1987), Beach et al. (2000), Kayis e Kara (2005), Slack (2005) e Gerwin (2005), que defendem que diferentes situações de manufatura estão sujeitas a diferentes tipos de incerteza e variações, requerendo diferentes tipos de flexibilidade.

Com respeito a esses diferentes tipos de flexibilidade, observa-se a existência de uma proliferação de taxonomias, muitas vezes conflitantes e sobrepostas (D'SOUZA; WILLIAMS, 2000; UPTON, 1995; SAWHNEY, 2006), motivo pelo qual foram selecionados doze diferentes tipos para utilização no instrumento de coleta de dados:

Flexibilidade de entrega;

Flexibilidade de expansão;

Flexibilidade de máquina;

Flexibilidade de mão de obra;

Flexibilidade de mix;

Flexibilidade de modificação;

Flexibilidade de movimentação de material;

Flexibilidade de operação;

Flexibilidade de produção;

Flexibilidade de produto;

Flexibilidade de roteamento; e

Flexibilidade de volume.

A escolha desses doze tipos foi fundamentada em Slack (1983), Gupta e Goyal (1989), Koste e Malhotra (1999) e Vokurka e O'Leary-Kelly (2000) cujas pesquisas já foram citadas anteriormente.

Quanto ao poder de atuação de cada tipo de flexibilidade para a solução de problemas na manufatura, formularam-se questões específicas no instrumento de coleta de dados para esse quesito, sendo seus resultados organizados sob a forma de quadros. Para uma melhor compreensão das informações dispostas nesses quadros, a seguir apresentados, se fazem necessários alguns comentários sobre os elementos que os compõem:

A coluna 'tipos de flexibilidade' informa os principais tipos de flexibilidade que foram abordados na presente pesquisa, sendo uma parte pré-preenchida no instrumento de coleta de dados. As demais colunas do quadro, que se referem à avaliação dos respondentes, estão diretamente ligadas e relacionadas ao tipo de flexibilidade dessa coluna (primeira coluna).

As colunas '1', '2', '3', '4' e '5' se referem ao grau da avaliação que foi imputado para cada tipo de flexibilidade, em que ' 1 ' significa que a flexibilidade avaliada não ajuda em nada na solução de problemas na manufatura; '2' significa que ajuda pouco; ' 3 ' significa que ajuda razoavelmente; ' 4 ' significa que ajuda bastante; e ' 5 ' significa que a dimensão de flexibilidade de manufatura avaliada é imprescindível para a indústria. A marcação de cada coluna com uma letra ' $\mathrm{X}$ ' indica o julgamento que o respondente fez para cada tipo de flexibilidade. Uma vez haver cinco respondentes para cada empresa pesquisada, observa-se a existência de 5 ' $\mathrm{X}$ ' para cada linha do quadro.

A coluna 'média' e 'mediana' apresentam as medidas de centro, oriundas da mensuração estatística das colunas de avaliação anteriormente descritas.

A coluna 'composição dos tipos de flexibilidade' mostra os tipos de flexibilidade de manufatura que os respondentes, diante da escassez de recursos para investimentos em flexibilidade de manufatura, escolheriam incorporar em seu ambiente de manufatura, formando assim as 'carteiras de flexibilidade', ou seja, as flexibilidades bem mais apropriadas para a solução de problemas na indústria.

A coluna 'fator flex.' calcula a competência de cada tipo de flexibilidade para o tratamento dos problemas que ocorrem na manufatura, segundo os seguintes critérios: média do julgamento de cada tipo de flexibilidade vezes o número de vezes que esse mesmo tipo de flexibilidade foi escolhido para compor uma 'carteira de flexibilidade'. O cálculo 
é realizado multiplicando-se o resultado da coluna da 'média', pelo número de quadrados da coluna de 'composição dos tipos de flexibilidade'. Ressalta-se que quanto maior for o Fator flex., mais importante é aquele tipo de flexibilidade para a solução de problemas na manufatura.

Uma vez explicado como cada quadro de análise de flexibilidade de manufatura foi construído, parte-se para sua análise.

Analisando os Quadros 5, 6, 7 e 8, observa-se que eles pertencem a empresas de diferentes ramos de atividade. Tal procedimento foi proposital, com vistas a investigar as demandas das flexibilidades de manufatura em distintos segmentos industriais e, também, verificar se haveria uma heterogeneidade da percepção dos entrevistados sobre a capacidade de atuação de cada tipo de flexibilidade na solução de problemas na manufatura. Após uma cuidadosa observação nos Quadros 5 ao 8, constata-se que:

- Com exceção da flexibilidade de volume, cuja média aparece nas quatro empresas pesquisadas com um escore que varia entre 4,4 e 4,6, a prioridade por demais flexibilidades são díspares. $\mathrm{Na}$ indústria química, por exemplo, os tipos de flexibilidade com maiores escores são as flexibilidade de volume e de mix (empatadas com 4,6); na indústria de vidros, observa-se um empate entre as flexibilidades que mais auxiliam na solução de problemas nesse tipo de indústria, que são as flexibilidades de entrega e de expansão (empatadas com 5,0); na indústria de equipamentos, as flexibilidades de máquina, mão de obra, mix e produto estão com um escore igual a 5,0. Na indústria de pneus, as flexibilidades mais demandadas são as de máquina e mão de obra (média de 4,6 para ambas).

- A indústria de equipamentos, de todas as quatro empresas pesquisadas, é a que mais utiliza flexibilidades de manufatura, adotando as flexibilidades de máquina $(5,0)$, mão de obra $(5,0)$, mix $(5,0)$, produto $(5,0)$, modificação $(4,6)$, volume $(4,4)$ e entrega $(4,2)$ para a solução de problemas.

- A indústria de vidros, das oito empresas, é a que menos utiliza flexibilidades de manufatura, avaliando a maioria das dimensões como flexibilidades que pouco ajudam na solução de problemas desse ramo de atividade.

Para facilitar essa análise, desenvolveu-se o Quadro 9, no qual o valor de cada Média Geral dos Fatores de Flexibilidade (MFF) das quatro empresas pesquisadas foi obtido por meio da média simples das quatro colunas nas quais estão os Fatores de Flexibilidade (FF), que, por sua vez, são os produtos dos respectivos valores das colunas referentes às Médias das avaliações sobre a ajuda que a flexibilidade proporciona à manufatura $(\mathrm{M}) \mathrm{e}$ às Composições dos tipos de flexibilidade de manufatura primordiais para investimento (CTF).

Observando-se o Quadro 9, constata-se que, de uma forma geral, a flexibilidade de mão de obra $(\mathrm{MFF}=17,70)$ e a flexibilidade de volume $(\mathrm{MFF}=16,90)$ possuem os maiores escores, sendo, portanto, as flexibilidades mais adequadas, segundo a percepção dos respondentes, para compor uma carteira de flexibilidade em três das quatro empresas pesquisadas.

Quadro 5. Análise de flexibilidade de manufatura na indústria química.

\begin{tabular}{|c|c|c|c|c|c|c|c|c|c|}
\hline \multicolumn{10}{|c|}{ Indústria química - análise de flexibilidade de manufatura } \\
\hline \multirow[t]{2}{*}{$\begin{array}{c}\text { Tipos de } \\
\text { flexibilidade }\end{array}$} & \multicolumn{7}{|c|}{$\begin{array}{l}\text { Classificação: não ajuda (1); ajuda pouco (2); ajuda razoavelmente } \\
\text { (3); ajuda bastante (4); é imprescindível (5) }\end{array}$} & \multirow{2}{*}{$\begin{array}{l}\text { Composição } \\
\text { dos tipos de } \\
\text { flexibilidade }\end{array}$} & \multirow[t]{2}{*}{$\begin{array}{l}\text { Fator } \\
\text { Flex. }\end{array}$} \\
\hline & 1 & 2 & 3 & 4 & 5 & Mediana & Média & & \\
\hline Entrega & $x$ & $x \times x$ & $x$ & & & 2,0 & 2,0 & & 0,0 \\
\hline Expansão & & & $x \times x$ & $x \times$ & & 3,0 & 3,4 & - & 3,4 \\
\hline Máquina & & $\times x$ & $x \times x$ & & & 3,0 & 2,6 & & 0,0 \\
\hline Mão de obra & & & $\times$ & $x \times x$ & $\times$ & 4,0 & 4,0 & man & 16,0 \\
\hline $\operatorname{Mix}$ & & & & $\times \times$ & $x \times x$ & 5,0 & 4,6 & घn日 & 18,4 \\
\hline Modificação & & $x \times x \times$ & $x$ & & & 2,0 & 2,2 & & 0,0 \\
\hline Movimentação & $\times$ & $x \times x \times$ & & & & 2,0 & 1,8 & & 0,0 \\
\hline Operação & $x$ & $x \times x$ & $x$ & & & 2,0 & 2,0 & & 0,0 \\
\hline Produção & & & $x$ & & $x \times \times \times$ & 5,0 & 4,6 & mघn & 18,4 \\
\hline Produto & & & $x \times$ & $x \times x$ & & 4,0 & 3,6 & & 0,0 \\
\hline Roteamento & $x \times x$ & $x \times$ & & & & 1,0 & 1,4 & & 0,0 \\
\hline Volume & & & & $\times \times$ & $x \times x$ & 5,0 & 4,6 & man & 18,4 \\
\hline
\end{tabular}


Quadro 6. Análise de flexibilidade de manufatura na indústria de vidros.

\begin{tabular}{|c|c|c|c|c|c|c|c|c|c|}
\hline \multicolumn{10}{|c|}{ Indústria de vidros - análise de flexibilidade de manufatura } \\
\hline \multirow[t]{2}{*}{$\begin{array}{c}\text { Tipos de } \\
\text { flexibilidade }\end{array}$} & \multicolumn{7}{|c|}{$\begin{array}{c}\text { Classificação: não ajuda (1); ajuda pouco (2); ajuda razoavelmente } \\
\text { (3); ajuda bastante (4); é imprescindível (5) }\end{array}$} & \multirow{2}{*}{$\begin{array}{l}\text { Composição } \\
\text { dos tipos de } \\
\text { flexibilidade }\end{array}$} & \multirow[t]{2}{*}{$\begin{array}{l}\text { Fator } \\
\text { Flex. }\end{array}$} \\
\hline & 1 & 2 & 3 & 4 & 5 & Mediana & Média & & \\
\hline Entrega & & & & & $x \times \times \times x$ & 5,0 & 5,0 & manna & 25,0 \\
\hline Expansão & & & & & $x \times \times \times x$ & 5,0 & 5,0 & mann & 25,0 \\
\hline Máquina & & $x \times x$ & $x \times$ & & & 2,0 & 2,4 & & 0,0 \\
\hline Mão de obra & & & $x \times x$ & $x \times$ & & 3,0 & 3,4 & m & 6,8 \\
\hline Mix & & $\times \times \times$ & $x \times$ & & & 2,0 & 2,4 & & 0 \\
\hline Modificação & & & $x \times$ & $x \times$ & $x$ & 4,0 & 3,8 & - & 3,8 \\
\hline Movimentação & $x$ & $x \times x$ & $\times$ & & & 2,0 & 2,0 & & 0,0 \\
\hline Operação & $x$ & & $x \times x \times$ & & & 3,0 & 2,6 & & 0,0 \\
\hline Produção & & $x \times$ & $x \times x$ & & & 3,0 & 2,6 & & 0,0 \\
\hline Produto & $x$ & $\times$ & $x \times x$ & & & 3,0 & 2,4 & & 0,0 \\
\hline Roteamento & $x \times$ & $x \times x$ & & & & 2,0 & 1,6 & & 0,0 \\
\hline Volume & & & & $x \times$ & $x \times x$ & 5,0 & 4,6 & घant & 18,4 \\
\hline
\end{tabular}

Quadro 7. Análise de flexibilidade de manufatura na indústria de equipamentos.

\begin{tabular}{|c|c|c|c|c|c|c|c|c|c|}
\hline \multicolumn{10}{|c|}{ Indústria de equipamentos - análise de flexibilidade de manufatura } \\
\hline \multirow[t]{2}{*}{$\begin{array}{c}\text { Tipos de } \\
\text { flexibilidade }\end{array}$} & \multicolumn{7}{|c|}{$\begin{array}{l}\text { Classificação: não ajuda (1); ajuda pouco (2); ajuda razoavelmente } \\
\text { (3); ajuda bastante (4); é imprescindível (5) }\end{array}$} & \multirow{2}{*}{$\begin{array}{l}\text { Composição } \\
\text { dos tipos de } \\
\text { flexibilidade }\end{array}$} & \multirow[t]{2}{*}{$\begin{array}{l}\text { Fator } \\
\text { Flex. }\end{array}$} \\
\hline & 1 & 2 & 3 & 4 & 5 & Mediana & Média & & \\
\hline Entrega & & & $x$ & $x \times$ & $x \times$ & 4,0 & 4,2 & 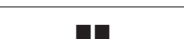 & 8,4 \\
\hline Expansão & & & $x \times x \times$ & & $x$ & 3,0 & 3,4 & - & 3,4 \\
\hline Máquina & & & & & $x \times x \times x$ & 5,0 & 5,0 & mann & 25,0 \\
\hline Mão de obra & & & & & $x \times x \times x$ & 5,0 & 5,0 & 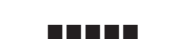 & 25,0 \\
\hline Mix & & & & & $x \times \times \times x$ & 5,0 & 5,0 & gman & 25,0 \\
\hline Modificação & & & & $x \times$ & $x \times x$ & 5,0 & 4,6 & ma & 13,8 \\
\hline Movimentação & & & $x \times x$ & $\times$ & $\times$ & 3,0 & 3,6 & ! & 3,6 \\
\hline Operação & & & $x \times x$ & $x x$ & & 3,0 & 3,4 & & 0,0 \\
\hline Produção & & & $x \times x \times$ & $\times$ & & 3,0 & 3,2 & & 0,0 \\
\hline Produto & & & & & $x \times x \times x$ & 5,0 & 5,0 & gman & 25,0 \\
\hline Roteamento & & & $x \times x$ & $x x$ & & 3,0 & 3,4 & & 0,0 \\
\hline Volume & & & $\times$ & $x$ & $x \times x$ & 5,0 & 4,4 & man & 13,2 \\
\hline
\end{tabular}

Quadro 8. Análise de flexibilidade de manufatura na indústria de pneus.

\begin{tabular}{|c|c|c|c|c|c|c|c|c|c|}
\hline \multicolumn{10}{|c|}{ Indústria de pneus - análise de flexibilidade de manufatura } \\
\hline \multirow[t]{2}{*}{$\begin{array}{c}\text { Tipos de } \\
\text { flexibilidade }\end{array}$} & \multicolumn{7}{|c|}{$\begin{array}{l}\text { Classificação: não ajuda (1); ajuda pouco (2); ajuda razoavelmente } \\
\text { (3); ajuda bastante (4); é imprescindível (5) }\end{array}$} & \multirow{2}{*}{$\begin{array}{l}\text { Composição } \\
\text { dos tipos de } \\
\text { flexibilidade }\end{array}$} & \multirow[t]{2}{*}{$\begin{array}{l}\text { Fator } \\
\text { Flex. }\end{array}$} \\
\hline & 1 & 2 & 3 & 4 & 5 & Mediana & Média & & \\
\hline Entrega & & $x$ & $x \times x$ & $x$ & & 3,0 & 3,0 & ! & 3,0 \\
\hline Expansão & & & $\times$ & $x \times$ & $x \times$ & 4,0 & 4,2 & ח & 8,4 \\
\hline Máquina & & & & $x \times$ & $x \times x$ & 5,0 & 4,6 & man & 18,4 \\
\hline Mão de obra & & & & $x \times$ & $x \times x$ & 5,0 & 4,6 & mener & 23,0 \\
\hline Mix & & & $x \times x \times$ & $\times$ & & 3,0 & 3,2 & & 0,0 \\
\hline Modificação & $x$ & $x$ & $x \times x$ & & & 3,0 & 2,4 & & 0,0 \\
\hline Movimentação & $x$ & $x$ & $x \times x$ & & & 3,0 & 2,4 & & 0,0 \\
\hline Operação & $x$ & $x$ & $x \times x$ & & & 3,0 & 2,4 & & 0,0 \\
\hline Produção & & & $x \times x \times$ & & $x$ & 3,0 & 3,4 & - & 3,4 \\
\hline Produto & $x$ & $x \times$ & $x \times$ & & & 2,0 & 2,2 & & 0,0 \\
\hline Roteamento & $x$ & $\times$ & $x \times x$ & & & 3,0 & 2,4 & & 0,0 \\
\hline Volume & & & & $x \times x$ & $x \times$ & 4,0 & 4,4 & घnn & 17,6 \\
\hline
\end{tabular}


Continuando com a análise de resultados, os Quadros 10 ao 13 condensarão a tabulação dos dados coletados nos instrumentos de coletas de dados aplicados à quatro empresas de mesmo segmento industrial, ou seja, em quatro montadoras de veículos. Ressalta-se que esses quadros possuem o mesmo formato daqueles utilizados para a tabulação dos dados das quatro empresas anteriormente pesquisadas. Aqui, ao contrário do bloco anterior, no qual as empresas pertenciam a ramos de atividade diferentes, procurou-se verificar se haveria uma homogeneidade da percepção dos entrevistados sobre a capacidade de atuação de cada tipo de flexibilidade na solução de problemas na manufatura.

Após análise nos quadros sobre a análise de flexibilidade na manufatura nas montadoras de veículos (Quadros 10 ao 13), constata-se que as flexibilidades que possuem maior poder de solução de problemas na manufatura, nesse segmento de empresas, são as flexibilidades de mix $(4,2 ; 4,6 ; 4,8$ e 4,8) [4,6], de volume $(4,6 ; 4,4 ; 4,6 ; 4,6)[4,55]$, de máquina $(4,6$; 4,$4 ; 4,8$ e 4,4) [4,55], de operação $(4,6 ; 5,0 ; 4,0$; e 4,2$)[4,45]$, de mão de obra $(4,4 ; 4,6 ; 4,4$ e 4,4$)$ [4,45], de expansão $(4,2 ; 4,0 ; 4,6$ e 4,6) [4,35] e de roteamento $(4,4 ; 4,0 ; 4,4$ e 3,6$)[4,10]$, em que os números entre parênteses indicam a média em cada montadora pesquisada e o número entre colchetes indica a média dos números entre parênteses.

Também foi elaborado um quadro de apoio (Quadro 14) para proporcionar uma melhor análise dos resultados da atuação da flexibilidade de manufatura nas montadoras de veículos, conforme acima.

Observando-se o Quadro 14, constata-se que a flexibilidade de operação (MFF = 19,20), a flexibilidade

Quadro 9. Resumo da análise de flexibilidade de manufatura em quatro das oito empresas pesquisadas.

\begin{tabular}{|c|c|c|c|c|c|c|c|c|c|c|c|c|c|}
\hline \multirow{2}{*}{$\begin{array}{c}\text { Tipos de } \\
\text { flexibilidade }\end{array}$} & \multicolumn{3}{|c|}{ Química } & \multicolumn{3}{|c|}{ Vidro } & \multicolumn{3}{|c|}{ Equipamento } & \multicolumn{3}{|c|}{ Pneus } & \multirow[t]{2}{*}{ MFF } \\
\hline & $\mathbf{M}$ & CTF & FF & $\mathbf{M}$ & & FF & M & CTF & FF & $\mathbf{M}$ & CTF & FF & \\
\hline Entrega & 2,0 & & 0,0 & 5,0 & & 25,0 & 4,2 & m & 8,4 & 3,0 & घ & 3,0 & 9,10 \\
\hline Expansão & 3,4 & - & 3,4 & 5,0 & घann & 25,0 & 3,4 & घ & 3,4 & 4,2 & $\mathbf{m}$ & 8,4 & 10,05 \\
\hline Máquina & 2,6 & & 0,0 & 2,4 & & 0,0 & 5,0 & घun日u & 25,0 & 4,6 & mama & 18,4 & 10,85 \\
\hline Mão de obra & 4,0 & שn & 16,0 & 3,4 & $\mathbf{m}$ & 6,8 & 5,0 & 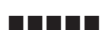 & 25,0 & 4,6 & 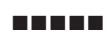 & 23,0 & 17,70 \\
\hline Mix & 4,6 & שn & 18,4 & 2,4 & & 0 & 5,0 & & 25,0 & 3,2 & & 0,0 & 10,85 \\
\hline Modificação & 2,2 & & 0,0 & 3,8 & - & 3,8 & 4,6 & घn & 13,8 & 2,4 & & 0,0 & 4,40 \\
\hline Movimentação & 1,8 & & 0,0 & 2,0 & & 0,0 & 3,6 & ! & 3,6 & 2,4 & & 0,0 & 0,90 \\
\hline Operação & 2,0 & & 0,0 & 2,6 & & 0,0 & 3,4 & & 0,0 & 2,4 & & 0,0 & 0,00 \\
\hline Produção & 4,6 & $\mathbf{m} \mathbf{m}$ & 18,4 & 2,6 & & 0,0 & 3,2 & & 0,0 & 3,4 & - & 3,4 & 5,45 \\
\hline Produto & 3,6 & & 0,0 & 2,4 & & 0,0 & 5,0 & घn日m & 25,0 & 2,2 & & 0,0 & 6,25 \\
\hline Roteamento & 1,4 & & 0,0 & 1,6 & & 0,0 & 3,4 & & 0,0 & 2,4 & & 0,0 & 0,00 \\
\hline Volume & 4,6 & صn & 18,4 & 4,6 & घn日 & 18,4 & 4,4 & m & 13,2 & 4,4 & man & 17,6 & 16,90 \\
\hline
\end{tabular}

$\mathrm{M}=$ Média das avaliações sobre a ajuda que a flexibilidade proporciona à manufatura; CTF = Composição dos tipos de flexibilidade de manufatura primordiais para investimento; FF = Fator de flexibilidade que associa as duas medidas anteriores; MFF $=$ Média geral dos fatores de flexibilidade das quatro empresas pesquisadas.

Quadro 10. Análise de flexibilidade de manufatura na montadora de veículos um.

\begin{tabular}{|c|c|c|c|c|c|c|c|c|c|}
\hline \multicolumn{10}{|c|}{ Montadora de veículos um - análise de flexibilidade de manufatura } \\
\hline \multirow[t]{2}{*}{$\begin{array}{c}\text { Tipos de } \\
\text { flexibilidade }\end{array}$} & \multicolumn{7}{|c|}{$\begin{array}{l}\text { Classificação: não ajuda (1); ajuda pouco (2); ajuda } \\
\text { razoavelmente (3); ajuda bastante (4); é imprescindível (5) }\end{array}$} & \multirow{2}{*}{$\begin{array}{l}\text { Composição } \\
\text { dos tipos de } \\
\text { flexibilidade }\end{array}$} & \multirow[t]{2}{*}{$\begin{array}{l}\text { Fator } \\
\text { Flex. }\end{array}$} \\
\hline & 1 & 2 & 3 & 4 & 5 & Mediana & Média & & \\
\hline Entrega & & & $x \times$ & $x \times$ & $x$ & 4,0 & 3,8 & $\square$ & 3,8 \\
\hline Expansão & & & $\times$ & $\times x$ & $x \times$ & 4,0 & 4,2 & $\mathbf{m} \mathbf{n}$ & 12,6 \\
\hline Máquina & & & & $x \times$ & $x \times x$ & 5,0 & 4,6 & man & 18,4 \\
\hline Mão de obra & & & & $x \times x$ & $x x$ & 4,0 & 4,4 & $\mathbf{m} \mathbf{m}$ & 13,2 \\
\hline Mix & & & $x$ & $x \times$ & $x x$ & 4,0 & 4,2 & ma & 12,6 \\
\hline Modificação & & $x x$ & $x$ & $\times$ & $x$ & 3,0 & 3,2 & घ & 3,2 \\
\hline Movimentação & $x$ & & $x$ & $x \times x$ & & 4,0 & 3,2 & & 0,0 \\
\hline Operação & & & & $x \times$ & $x \times x$ & 5,0 & 4,6 & घघEघ & 23,0 \\
\hline Produção & & & & $x \times x \times x$ & & 4,0 & 4,0 & & 0,0 \\
\hline Produto & & & $x \times x \times x$ & & & 3,0 & 3,0 & & 0,0 \\
\hline Roteamento & & & & $\times \times x$ & $\times \times$ & 4,0 & 4,4 & man & 17,6 \\
\hline Volume & & & & $x \times$ & $x \times x$ & 5,0 & 4,6 & an & 13,8 \\
\hline
\end{tabular}


Quadro 11. Análise de flexibilidade de manufatura na montadora de veículos dois.

\begin{tabular}{|c|c|c|c|c|c|c|c|c|c|}
\hline \multicolumn{10}{|c|}{ Montadora de veículos dois - análise de flexibilidade de manufatura } \\
\hline \multirow[t]{2}{*}{$\begin{array}{l}\text { Tipos de } \\
\text { flexibilidade }\end{array}$} & \multicolumn{7}{|c|}{$\begin{array}{l}\text { Classificação: não ajuda (1); ajuda pouco (2); ajuda } \\
\text { razoavelmente (3); ajuda bastante (4); é imprescindível (5) }\end{array}$} & \multirow{2}{*}{$\begin{array}{l}\text { Composição } \\
\text { dos tipos de } \\
\text { flexibilidade }\end{array}$} & \multirow[t]{2}{*}{$\begin{array}{l}\text { Fator } \\
\text { Flex. }\end{array}$} \\
\hline & 1 & 2 & 3 & 4 & 5 & Mediana & Média & & \\
\hline Entrega & & $x$ & $x \times$ & & $x \times$ & 3,0 & 3,6 & $\mathbf{m}$ & 7,20 \\
\hline Expansão & & & $\times$ & $x \times x$ & $x$ & 4,0 & 4,0 & $\mathbf{m}$ & 12,0 \\
\hline Máquina & & & $x$ & $\times$ & $x \times x$ & 5,0 & 4,4 & $\mathbf{m} \mathbf{m}$ & 17,6 \\
\hline Mão de obra & & & & $\times \times$ & $x \times x$ & 5,0 & 4,6 & man & 18,4 \\
\hline Mix & & & $x$ & & $x \times x \times$ & 5,0 & 4,6 & man & 18,4 \\
\hline Modificação & & & $x \times x$ & $\times \times$ & & 3,0 & 3,4 & & 0,0 \\
\hline Movimentação & & & $x \times x \times$ & $\times$ & & 3,0 & 3,2 & & 0,0 \\
\hline Operação & & & & & $\times \times \times \times \times$ & 5,0 & 5,0 & घnघm & 25,0 \\
\hline Produção & & & $\times \times x$ & $x \times$ & & 3,0 & 3,4 & & 0,0 \\
\hline Produto & & & $x \times x \times x$ & & & 3,0 & 3,0 & & 0,0 \\
\hline Roteamento & & & $x$ & $x \times x$ & $x$ & 4,0 & 4,0 & $\mathbf{m}$ & 8,0 \\
\hline Volume & & & & $x \times x$ & $x x$ & 4,0 & 4,4 & $\mathbf{n}$ & 8,8 \\
\hline
\end{tabular}

Quadro 12. Análise de flexibilidade de manufatura na montadora de veículos três.

\begin{tabular}{|c|c|c|c|c|c|c|c|c|c|}
\hline \multicolumn{10}{|c|}{ Montadora de veículos três - análise de flexibilidade de manufatura } \\
\hline \multirow[t]{2}{*}{$\begin{array}{c}\text { Tipos de } \\
\text { flexibilidade }\end{array}$} & \multicolumn{7}{|c|}{$\begin{array}{l}\text { Classificação: não ajuda (1); ajuda pouco (2); ajuda } \\
\text { razoavelmente (3); ajuda bastante (4); é imprescindível (5) }\end{array}$} & \multirow{2}{*}{$\begin{array}{l}\text { Composição } \\
\text { dos tipos de } \\
\text { flexibilidade }\end{array}$} & \multirow[t]{2}{*}{$\begin{array}{l}\text { Fator } \\
\text { Flex. }\end{array}$} \\
\hline & 1 & 2 & 3 & 4 & 5 & Mediana & Média & & \\
\hline Entrega & & & $\times \times$ & $x \times x$ & & 4,0 & 3,6 & - & 3,60 \\
\hline Expansão & & & & $\times \times$ & $x \times x$ & 5,0 & 4,6 & ma & 13,8 \\
\hline Máquina & & & & $\times$ & $x \times \times \times$ & 5,0 & 4,8 & 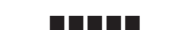 & 24,0 \\
\hline Mão de obra & & & & $x \times x$ & $x \times$ & 4,0 & 4,4 & $\mathbf{m} \mathbf{m}$ & 13,2 \\
\hline Mix & & & & $\times$ & $x \times x \times$ & 5,0 & 4,8 & man & 19,2 \\
\hline Modificação & & $x \times$ & $x \times x$ & & & 3,0 & 2,6 & & 0,0 \\
\hline Movimentação & $x$ & $x \times$ & $x x$ & & & 2,0 & 2,2 & & 0,0 \\
\hline Operação & & $x$ & & $\times x$ & $x \times$ & 4,0 & 4,0 & घ日 & 12,0 \\
\hline Produção & & & $x \times x$ & $\times$ & $\times$ & 3,0 & 3,6 & घ & 3,6 \\
\hline Produto & & $x \times$ & $x \times x$ & & & 3,0 & 2,6 & & 0,0 \\
\hline Roteamento & & & $\times$ & $x$ & $\times \times \times$ & 5,0 & 4,4 & घu & 13,2 \\
\hline Volume & & & & $x \times$ & $x \times x$ & 5,0 & 4,6 & man & 18,4 \\
\hline
\end{tabular}

Quadro 13. Análise de flexibilidade de manufatura na montadora de veículos quatro.

\begin{tabular}{|c|c|c|c|c|c|c|c|c|c|}
\hline \multicolumn{10}{|c|}{ Montadora de veículos quatro - análise de flexibilidade de manufatura } \\
\hline \multirow[t]{2}{*}{$\begin{array}{c}\text { Tipos de } \\
\text { flexibilidade }\end{array}$} & \multicolumn{7}{|c|}{$\begin{array}{l}\text { Classificação: não ajuda (1); ajuda pouco (2); ajuda razoavelmente } \\
\text { (3); ajuda bastante (4); é imprescindível (5) }\end{array}$} & \multirow{2}{*}{$\begin{array}{l}\text { Composição } \\
\text { dos tipos de } \\
\text { flexibilidade }\end{array}$} & \multirow[t]{2}{*}{$\begin{array}{l}\text { Fator } \\
\text { Flex. }\end{array}$} \\
\hline & 1 & 2 & 3 & 4 & 5 & Mediana & Média & & \\
\hline Entrega & & & $x \times$ & $\times \times \times$ & & 4,0 & 3,6 & - & 3,6 \\
\hline Expansão & & & & $\times \times$ & $\times \times \times$ & 5,0 & 4,6 & $\mathbf{m}$ & 13,8 \\
\hline Máquina & & & & $\times \times \times$ & $\times \times$ & 4,0 & 4,4 & घn & 13,2 \\
\hline Mão de obra & & & & $\times \times \times$ & $x \times$ & 4,0 & 4,4 & ma & 13,2 \\
\hline Mix & & & & $\times$ & $x \times \times \times$ & 5,0 & 4,8 & घnum & 24,0 \\
\hline Modificação & & & $\times \times \times \times$ & $x$ & & 3,0 & 3,2 & & 0,0 \\
\hline Movimentação & $x \times$ & $\times x$ & $\times$ & & & 2,0 & 1,8 & & 0,0 \\
\hline Operação & & & & $\times \times \times \times$ & $x$ & 4,0 & 4,2 & man & 16,8 \\
\hline Produção & & $x$ & $x \times$ & $\times$ & $x$ & 3,0 & 3,4 & घ & 3,4 \\
\hline Produto & & $\times \times \times \times$ & $\times$ & & & 2,0 & 2,2 & & 0,0 \\
\hline Roteamento & & & $\times x$ & $\times \times \times$ & & 4,0 & 3,6 & $\mathbf{m}$ & 7,2 \\
\hline Volume & & & & $x \times$ & $x \times x$ & 5,0 & 4,6 & ma & 13,8 \\
\hline
\end{tabular}


Quadro 14. Resumo da análise de flexibilidade de manufatura nas quatro montadoras de veículos pesquisadas.

\begin{tabular}{|c|c|c|c|c|c|c|c|c|c|c|c|c|c|}
\hline \multirow{2}{*}{$\begin{array}{c}\text { Tipos de } \\
\text { flexibilidade }\end{array}$} & \multicolumn{3}{|c|}{ Montadora 1} & \multicolumn{3}{|c|}{ Montadora 2} & \multicolumn{3}{|c|}{ Montadora 3} & \multicolumn{3}{|c|}{ Montadora 4} & \multirow[t]{2}{*}{ MFF } \\
\hline & M & CTF & FF & M & & FF & M & CTF & FF & M & CTF & FF & \\
\hline Entrega & 3,8 & ! & 3,8 & 3,6 & ma & 7,20 & 3,6 & ! & 3,60 & 3,6 & ! & 3,6 & 4,55 \\
\hline Expansão & 4,2 & $m$ & 12,6 & 4,0 & $m a n$ & 12,0 & 4,6 & $m$ & 13,8 & 4,6 & 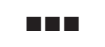 & 13,8 & 13,05 \\
\hline Máquina & 4,6 & man & 18,4 & 4,4 & " & 17,6 & 4,8 & gunan & 24,0 & 4,4 & man & 13,2 & 18,30 \\
\hline Mão de obra & 4,4 & man & 13,2 & 4,6 & " & 18,4 & 4,4 & घn! & 13,2 & 4,4 & man & 13,2 & 14,50 \\
\hline Mix & 4,2 & $\operatorname{men}$ & 12,6 & 4,6 & - & 18,4 & 4,8 & man日 & 19,2 & 4,8 & mennen & 24,0 & 18,55 \\
\hline Modificação & 3,2 & - & 3,2 & 3,4 & & 0,0 & 2,6 & & 0,0 & 3,2 & & 0,0 & 0,80 \\
\hline Movimentação & 3,2 & & 0,0 & 3,2 & & 0,0 & 2,2 & & 0,0 & 1,8 & & 0,0 & 0,00 \\
\hline Operação & 4,6 & manne & 23,0 & 5,0 & andm & 25,0 & 4,0 & mE & 12,0 & 4,2 & ana & 16,8 & 19,20 \\
\hline Produção & 4,0 & & 0,0 & 3,4 & & 0,0 & 3,6 & - & 3,6 & 3,4 & - & 3,4 & 1,75 \\
\hline Produto & 3,0 & & 0,0 & 3,0 & & 0,0 & 2,6 & & 0,0 & 2,2 & & 0,0 & 0,00 \\
\hline Roteamento & 4,4 & anan & 17,6 & 4,0 & m & 8,0 & 4,4 & חI & 13,2 & 3,6 & ח & 7,2 & 11,50 \\
\hline Volume & 4,6 & ma & 13,8 & 4,4 & m & 8,8 & 4,6 & anen & 18,4 & 4,6 & ma & 13,8 & 13,70 \\
\hline
\end{tabular}

$\mathrm{M}=$ Média das avaliações sobre a ajuda que a flexibilidade proporciona à manufatura; CTF = Composição dos tipos de flexibilidade de manufatura primordiais para investimento; FF = Fator de flexibilidade, que associa as duas medidas anteriores; e MFF = Média geral dos fatores de flexibilidade das quatro montadoras de veículos.

de mix (MFF $=18,55)$ e a flexibilidade de máquina $(\mathrm{MFF}=18,30)$ possuem os maiores escores, sendo, portanto, as flexibilidades mais adequadas, segundo a percepção dos respondentes, para compor uma carteira de flexibilidade na indústria automotiva.

\section{Conclusões}

De forma similar ao que ocorre no mercado de ações, observou-se que, quando a temática é flexibilidade de manufatura para atuação contra os riscos e as incertezas no contexto operacional das organizações fabris, os diferentes tipos de flexibilidade possuem comportamento análogo (dentro daquilo que se propôs a presente pesquisa) às ações negociadas nas bolsas de valores.

Nos estudos de Parker e Wirth (1999), por exemplo, constatou-se que o incremento da flexibilidade de máquina contribui para o desenvolvimento de quase todos os tipos de dimensões, exceto a flexibilidade de volume, que possui relação negativa (Figura 8). Outras pesquisas sobre o relacionamento entre as dimensões da flexibilidade de manufatura também levantaram a existência de relações complexas e trade-offs entre os diferentes tipos de flexibilidade (SUAREZ; CUSMANO; FINE, 1996; KOSTE; MALHOTRA, 2000).

Por esse motivo, aqui se julgou viável a composição de carteiras de flexibilidade de manufatura, segundo a percepção daqueles que estão envolvidos diariamente com o processo produtivo das indústrias. A razão disso é para que fosse possível uma ideal ponderação entre seus diferentes tipos, de forma a proporcionar a minimização dos impactos dos riscos operacionais, sem exigir a necessidade de investimentos desnecessários, ou com pouco poder de atuação, na solução dos problemas que ocorrem no cotidiano da manufatura das organizações industriais.

A pesquisa não teve a intenção de encontrar uma fronteira eficiente de flexibilidade de manufatura (se é que ela existe), a exemplo do que ocorre no mercado de ações. Entretanto, a revisão da literatura mostrou que existem trade-offs na flexibilidade e que, desses trade-offs, identificam-se relações negativas e positivas entre os diferentes tipos de flexibilidade de manufatura. Isso significa que, ao se investir em tipos de flexibilidades que possuem uma alta correlação positiva, menos investimentos em flexibilidade serão necessários. Ao se investir em flexibilidades com uma correlação negativa, mais investimentos serão demandados (exatamente o oposto do que ocorre no mercado de ações).

De um modo geral, as montadoras de veículos, por exemplo, preferem fazer composição de flexibilidades com as flexibilidades de operação, de mix e de máquina; a indústria química, por sua vez, compõe 'carteiras de flexibilidade' com as flexibilidades de volume, mix, produção e mão de obra; a indústria de vidros adere à seleção das flexibilidades de entrega, de expansão e de volume; a indústria de equipamentos prefere as flexibilidades de máquina, mão de obra, mix e produto; e, por fim, a indústria de pneus aglutina as flexibilidades de mão de obra, máquina e volume para a minimização de investimentos em flexibilidades que, segundo a percepção dos respondentes dessa indústria, minimizarão os problemas na manufatura.

Por fim, constata-se que nenhuma dimensão de flexibilidade é repetida cinco vezes, ou seja, as demandas por flexibilidade são particulares para 
cada um dos cinco segmentos industriais analisados, tendo, é claro, a preferência industrial comum por alguns tipos, como é o caso das flexibilidades de mix, volume, máquina e mão de obra. Esses quatro tipos de flexibilidades foram citados, de forma distinta e em combinações diferentes, em três dos cinco segmentos industriais analisados.

\section{Referências}

ASSAF NETO, A. Mercado financeiro. 5. ed. São Paulo: Atlas, 2003.

BAYKASOGLU, A.; OZBAKIR, L. Analysing the effect of flexibility on manufacturing systems performance. Journal of Manufacturing Technology Management, v. 19, n. 2, p. 172-193, 2008.

BEACH, R. et al. A review of manufacturing Flexibility. European Journal of Operational Research, v. 122, n. 1, p. 41-57, 2000.

BENGTSSON, J.; OLHAGER, J. The impact of the product mix on the value of flexibility. The International Journal of Management Science, v. 30, n. 4, p. 265-273, 2002.

BOYLE, T. A. Towards best management practices for implementing manufacturing flexibility. Journal of Manufacturing Technology Management, v. 17, n. 1, p. 6-21, 2006.

BRIGHAM, E. F.; GAPENSKI, L. C.; EHRTARDT, M. C. Administração financeira: teoria e prática. São Paulo: Atlas, 2001.

CHANG, S. et al. Achieving manufacturing flexibility through entrepreneurial orientation. Industrial Management \& Data Systems, v. 107, n. 7, p. 997-1017, 2007.

CORRÊA, H. L. Flexibilidade estratégica na manufatura: incertezas e variabilidade de saída. Revista de Administração da USP, v. 29, n. 1, p. 33-41, 1994.

COX, T. Toward the measurement of manufacturing flexibility. Production and Inventory Management Journal, v. 30, n. 1, p. 68-72, 1989.

D'SOUZA, D. E.; WILLIAMS, F. P. Toward a taxonomy of manufacturing flexibility dimensions. Journal of Operations Management, v. 18, n. 5, p. 577-593, 2000.

DE TONI, A.; TONCHIA, S. Manufacturing flexibility: a literature review. International Journal of Production Research, v. 36, n. 6, p. 1587-1617, 1998.

GERWIN, D. An agenda for research on the flexibility of manufacturing processes. International Journal of Operations \& Production Management, v. 25, n. 12, p. 1171-1182, 2005.

GITMAN, L. J.; MADURA, J. Administração financeira: uma abordagem gerencial. São Paulo: Pearson, 2003.

GONÇALVES Jr., C.; PAMPLONA, E. O.; MONTEVECHI, J. A. B. Seleção de carteiras através do modelo de Markowitz para pequenos investidores (com o uso de planilhas eletrônicas). In: SIMPÓSIO DE ENGENHARIA DE PRODUÇÃO -SIMPEP,9, 2002, Bauru.

GUPTA, Y. P.; GOYAL, S. Flexibility of manufacturing systems: concept and measurements. European Journal of Operational Research, v. 43, n. 2, p. 119-135, 1989.

GUPTA, Y. P.; SOMERS, T. M. The measurement of manufacturing flexibility. European Journal of Operational Research, v. 60, n. 2, p. 166-182, 1992.

GUSTAVSSON, S. Flexibility and productivity in complex production processes. International Journal of Production Research, v. 22, n. 5, p. 801-808, 1984.

KARA, S.; KAYIS, B. Manufacturing flexibility and variability: an overview. Journal of Manufacturing Technology Management, v. 15, n. 6, p. 466-478, 2004.

KAYIS, B.; KARA, S. The supplier and customer contribution to manufacturing flexibility: australian manufacturing industry's perspective. Journal of Manufacturing Technology Management, v. 16, n. 7, p. 733-752, 2005.

KOSTE, L. L.; MALHOTRA, M. K. A theoretical framework for analyzing the dimensions of manufacturing flexibility. Journal of Operations Management, v.18, n. 1, p. 75-93, 1999.

KOSTE, L. L.; MALHOTRA, M. K. Trade-offs among the elements of flexibility: a comparison from the automotive industry. The International Journal of Management Science, v. 28, n. 6, p. 693-710, 2000.

LAKONISHOK, J.; SHLEIFER, A.; VISHNY, R. W. Contrarian investment, extrapolation, and risk. Journal of Finance, v. 49, n. 5, p. 1541-1578, 1994.

MARKOWITZ, H. Portfolio Selection. Journal of Finance, v. 7, n. 1, p. 77-91, 1952.

NORDAHL, H.; NILSSON, C. Managers' perceptions of flexibility in manufacturing: a study in the Swedish engineering industry. Integrated Manufacturing Systems, v. 7, n. 4, p. 22-33, 1996.

OKE, A. A framework for analyzing manufacturing flexibility. International Journal of Operations \& Production Management, v. 25, n. 10, p. 973-996, 2005.

PARKER, R. P.; WIRTH, A. Manufacturing flexibility: measures and relationships. European Journal of Operational Research, v. 118, n. 3, p. 429-449, 1999.

REID, D.; SANDERS, N. Gestão de operações. Rio de Janeiro: LTC, 2005.

ROSS, S. A; WESTERFIELD, R. W.; JAFFE, J. F. Administração Financeira. 2. ed. São Paulo: Atlas, 2002.

SAWHNEY, R. Interplay between uncertainty and flexibility across the value-chain: towards a transformation model of manufacturing flexibility. Journal of Operations Management, v. 24, n. 5, p. 476-493, 2006.

SCALA, J; PURDY, L.; SAFAYENI, F. Application of cybernetics to manufacturing flexibility: a systems perspective. Journal of Manufacturing Technology Management, v. 17, n. 1, p. 22-41, 2006.

SERRÃO, R. O. B. Um estudo sobre a flexibilidade de manufatura e sua percepção e efetivação em micro e pequenas empresas. 2001. p. 134. Dissertação (Mestrado) - Pontifícia Universidade Católica do Rio de Janeiro, Rio de Janeiro, 2001.

SETHI, A. K.; SETHI, S. P. Flexibility in manufacturing: a survey. The International Journal of Flexible 
Manufacturing Systems, v. 2, n. 4, p. 289-328, 1990.

SHARPE, W. F. Capital asset prices: a theory of market equilibrium under conditions of risk. The Journal of Finance, v. 19, n. 3, p. 425-442, 1964.

SLACK, N. Flexibility as a manufacturing objective. International Journal of Operations and Production Management, v. 3, n. 3, p. 4-13, 1983.

SLACK, N. The flexibility of manufacturing systems. International Journal of Operations \& Production Management, v. 25, n. 12, p. 1190-1200, 2005.

SUAREZ, F. F.; CUSUMANO, M. A.; FINE, C. H. An empirical study of flexibility in manufacturing. Sloan Management Review, v. 37, n. 1, p. 25-32, 1995.

SUAREZ, F. F.; CUSUMANO, M. A.; FINE, C. H. An empirical study of manufacturing flexibility in printed circuit board assembly. Operations Research, v. 44, n. 1, p. 223-240, 1996.

SWAMIDASS, P. M.; NEWELL, W. T. Manufacturing strategy, environmental uncertainty and performance: a path analytic model. Management Science, v. 33, n. 4, p. 509-524, 1987.

TREYNOR, J. L.; BLACK, F. How to use security analysis to improve portfolio selection. The Journal of Business, v. 46, n. 1 , p. 66-86, 1973.
TRIOLA, M. F. Introdução à estatística. 9. ed. Rio de Janeiro: LTC, 2005.

UPTON, D. M. Flexibility as process mobility: the management of plant capabilities for quick response manufacturing. Journal of Operations Management, v. 12 , n. 3-4, p. 205-224, 1995.

UPTON, D. M. The management of manufacturing flexibility. California Management Review, v. 36, n. 2, p. 72-89, 1994.

UPTON, D. M. Process range in manufacturing: an empirical study of flexibility. Management Science, v. 43, n. 8, p. 1079-1092, 1997.

VOKURKA, R. J.; O'LEARY-KELLY, S. W. A review of empirical research on manufacturing flexibility. Journal of Operations Management, v. 18, n. 4, p. 485-501, 2000 .

WAHAB, M. I. M.; WU, D.; LEE, C. A generic approach to measuring the machine flexibility of manufacturing systems. European Journal of Operational Research, v. 186, n. 1, p. 137-149, 2008.

ZUKIN, M.; DALCOL, P. R. Manufacturing flexibility: assessing managerial perception and utilization. The International Journal of Flexible Manufacturing Systems, v. 12, n. 1, p. 5-23, 2000. 